\title{
Primary intracerebral haemorrhage in the Jyväskylä region, Central Finland, 1985-89: incidence, case fatality rate, and functional outcome
}

\author{
R Fogelholm, M Nuutila, A-L Vuorela
}

\begin{abstract}
The age and sex specific incidence rates, the case fatality rates, and the functional outcome of patients with primary intracerebral haemorrhage occurring in a population of 116000 during a period of four years four months are presented. A total of 158 patients were identified, the diagnosis was confirmed in $78 \%$ by CT, and in $22 \%$ by necropsy. The crude annual incidence rate was 31/100 000 population, the age specific rates increased from two to 2221100000 from the age of $30-39$ to over 80 years. Men had higher incidence rates between the ages of 40 and 79 years. The short term case fatality rate was high, $27 \%$ of patients dying during the first day after onset of symptoms, and $50 \%$ were dead at 30 days. After the first month the probability of survival did not differ from an age- and sex-matched average population. Large haematoma volume had an adverse effect on the short term, old age (>70 years) on the long term survival. Ventricular extension, especially when combined with hydrocephalus was a bad omen for short term survival. Infratentorial and large basal ganglionic haematomas, and primary intraventricular haemorrhage carried a worse prognosis than haematomas of other locations. At the end of a median 32 month follow up 55 (35\%) of the patients were alive, $51 \%$ of these were independent in activities of daily living, $45 \%$ were dependent on outside help, and $4 \%$ needed constant nursing care. Old age ( $>70$ years), but not the haematoma volume or location, was associated with a poor functional recovery.
\end{abstract}

The main interest of numerous epidemiological studies on stroke has been in ischaemic cerebrovascular disease, and haemorrhagic strokes, but scant attention has been given to primary intracerebral haemorrhage (PICH). Most of these studies pre-date CT. During the past decade CT has been increasingly applied in these studies and reliable data on the different pathological entities have been obtained. $^{1-9}$ The annual incidence rates of PICH have generally been from 11 to 20 per 100000 population, and the diagnosis of PICH has been confirmed by CT in $37 \%-100 \%$ of the cases. The number of patients in most of these studies has, however, been too small to warrant firm conclusions regarding the case fatality rate and the functional outcome.
Since 1985 CT has been available in the Central Hospital of Central Finland and it has been included in the routine examination of stroke patients. On the other hand, because virtually all acute stroke patients from Jyväskylä and the surrounding communes, the Jyväskylä Region, are admitted to the Central Hospital, an epidemiological study on PICH seemed feasible. To make the study as comprehensive as possible, patients with the diagnosis made by necropsy were also included.

\section{Patients and methods}

The study included a population of 116033 living in the Jyväskylä Region (figure 1). The age and sex distribution of the study population 31 December 1987 is shown in table 1 (Central Statistical Office of Finland). The study population was slightly younger than the Finnish population, the proportions of people aged 65 years or older were $11.5 \%$ and $12.9 \%$, respectively.

The primary health care in Central Finland is provided by the Health Centres of the 32 communes, which have joined to form 11 larger Health Centre Districts. Because of a shortage of beds the Health Centres in the Jyväskylä Region send nearly all acute strokes to the Central Hospital. A survey performed in 1986 revealed that $92 \%$ of acute strokes occurring in this population were admitted to the Central Hospital, $2 \%$ died before arrival, and only $6 \%$ were treated in their Health Centres. After 1986 there has been no change in this situation.

Since 1982 nearly all stroke patients admitted to the Central Hospital were treated in the Department of Neurology. The exceptions are those patients with serious cardiac or metabolic problems who are first treated in the Department of Medicine. CT has been available since August 1985 in the hospital and this has enabled confirmation of pathological lesions causing stroke. The aim has been to perform CT on all acute stroke patients, preferably within the first few days after onset of symptoms. In $198990 \%$ of all stroke patients were examined with CT, and an additional $2-3 \%$ were diagnosed at necropsy.

This study included all PICH patients who were: a) permanently living in the Jyväskylä Region; b) for whom the onset of ICH occurred during the study period from 1 September 1985 to 31 December 1989, and c) in whom the diagnosis was confirmed by CT and/or necropsy. We excluded patients with traumatic haematomas as well as those with 


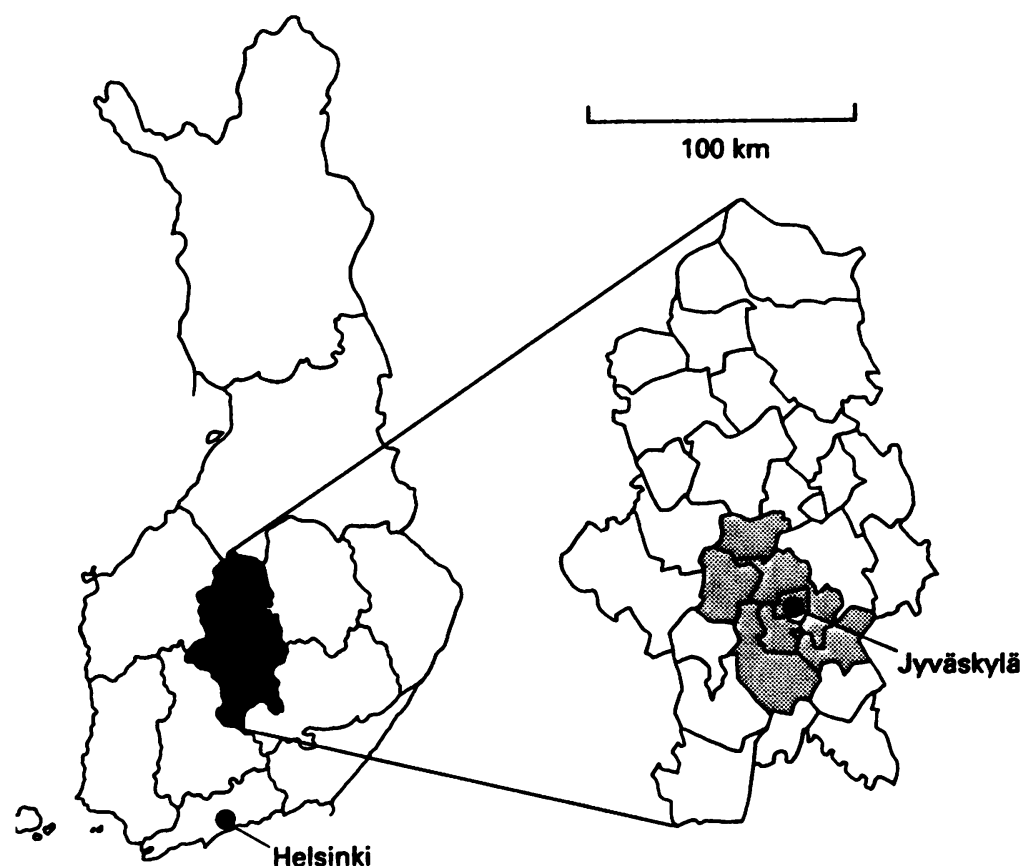

Figure 1 Map of Central Finland. The communes included in the fyväskylä Region are hatched. for 10 days or longer. In addition to the telephone interview, the medical records of all survivors were assessed to confirm the presence or absence, and pathology of recurrent strokes. The cause of death was determined on the basis of the death certificates and all relevant data in the hospital and necropsy records.

The CT scans were checked and the haematomas were located using the CT atlas of Kretschmann and Weinrich. ${ }^{12}$ Large haematomas were classified according to the lobe most affected. In the region of the basal ganglia (when the origin of the bleed could not be identified) they were named "basal ganglia" haematoma. The same principles were applied in haematomas diagnosed at necropsy. Carotid angiography was used to exclude bleeds from an arterial aneurysm in the frontal and temporal lobe haematomas adjacent to the interhaemispheric or the Sylvian fissure.

The haematoma volumes were calculated by a computer program. The area of the haematoma was measured planimetrically and it was multiplied by the thickness of the corresponding slice. The total volume was calculated by summing these subvolumes. The shift of the midline structures, pineal body and/or the third ventricle, was measured, and the presence of intraventricular blood and hydrocephalic dilatation of the cerebral ventricles was recorded.

The confidence intervals for incidence rates were calculated using the Schoenberg tables, ${ }^{13}$ for medians according to Campbell and Gardner, ${ }^{14}$ and for proportions according to Gardner and Altman. ${ }^{15}$ Life-tables were constructed as described by Colton. ${ }^{16}$ The crude incidence rates were adjusted to the age distribution of the Finnish population $1980^{17}$ by the direct method. ${ }^{16}$ The chi-square test was applied in the comparison of proportions, and the $t$ test in the comparison of means. nosis of ICH (ICD-8,ICD-9 code 431) were reviewed and from these relevant data were collected.

The patients were followed up to 31 August 1990. At the end of follow up all patients who had been discharged alive were contacted by telephone-in case of severe handicap or death the carer or a near relative was interviewed. Missing data concerning earlier health and living habits were completed, the possible occurrence of new strokes and the degree of independence in activities of daily living (ADL) was assessed applying the Rankin grading method. ${ }^{1011}$ The best functional grade achieved in ADL was also assessed in case of hospital death, provided the patient survived

Table 1 The population of Fyväskylä and the surrounding communes 31 December 1987

\begin{tabular}{lrrr}
\hline Age (years) & \multicolumn{1}{l}{ Men } & Women & \multicolumn{1}{c}{ Total } \\
\hline $0-29$ & 24921 & 23941 & 48862 \\
$30-39$ & 10355 & 10087 & 20442 \\
$40-49$ & 8175 & 8165 & 16340 \\
$50-59$ & 5488 & 6059 & 11547 \\
$60-69$ & 4073 & 5938 & 10011 \\
$70-79$ & 2308 & 4231 & 6539 \\
$80+$ & 646 & 1646 & 2292 \\
Total & 55966 & 60067 & 116033 \\
\hline
\end{tabular}

\section{Results}

During the study period 1 September 1985 to 31 December 1989 a total of 158 patients resident in the Jyväskylä Region were traced (table 2). The diagnosis was confirmed in 123 patients with CT, and in the other 35 by necropsy (fig 2), a total of 31 of the patients having both CT and necropsy. Eight (5\% of all patients) of the 35 patients with necropsy confirmation were found dead and had a medico-legal autopsy. The time interval between onset of symptoms and admission to the emergency room of the Central Hospital was short, the median delay was 2 hours, and $75 \%$ were admitted within 6 hours. Cerebral CT was performed within the first 24 hours after onset in $43 \%$, and within 72 hours in $90 \%$ of cases. The distribution of the location of the haematomas is shown in table 3.

The prevalence of various cardiovascular diseases was as follows: hypertension $46 \%$, coronary heart disease $22 \%$, atrial fibrillation $20 \%$, and ischaemic brain infarction $17 \%$. Twenty six $(16 \%)$ of the patients were on anticoagulation at the onset of PICH. 
Table 2 Age and sex distribution of the patients

\begin{tabular}{llllllll}
\hline & Age & & & & & & \\
\cline { 2 - 6 } Sex & $30-39$ & $40-49$ & $50-59$ & $60-69$ & $70-79$ & $80+$ & Total \\
\hline Men & 1 & 11 & 12 & 19 & 32 & 3 & 78 \\
Women & 1 & 3 & 8 & 21 & 28 & 19 & 80 \\
Total & 2 & 14 & 20 & 40 & 60 & 22 & 158 \\
\hline
\end{tabular}

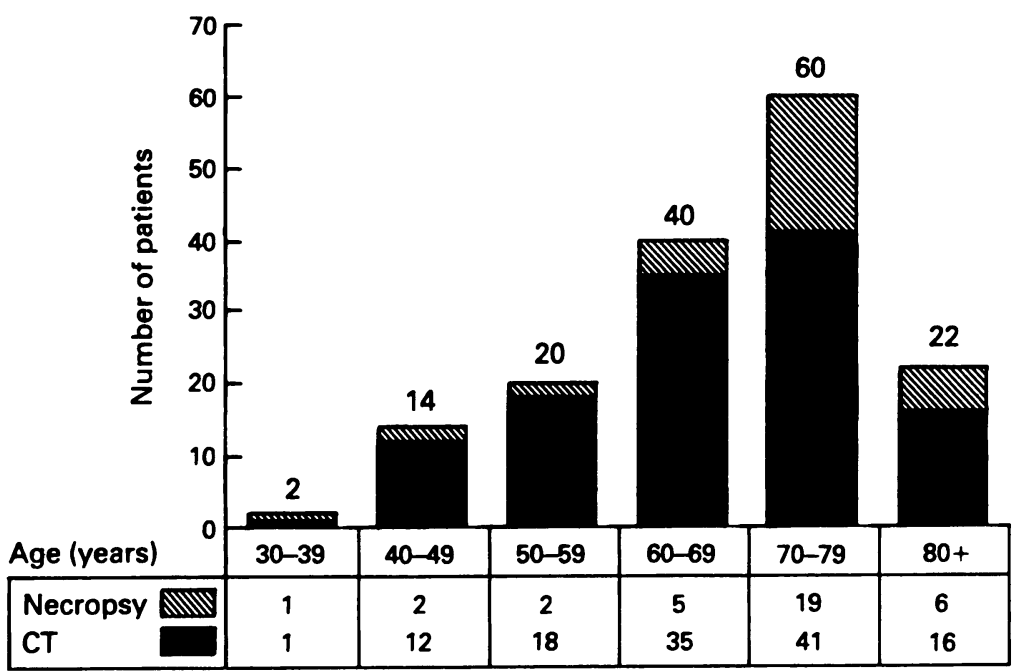

Figure 2 Numbers of patients with the diagnosis confirmed by either CT or necropsy, by age.

The crude incidence rate was $31 / 100000 /$ year, the age and sex specific annual incidence rates per 100000 population are shown in table 4 . The rate increased steeply by age, from $2 / 100000$ in the age $30-39$ years to $222 / 100000$ over the age of 80 years. The incidence rates for men were higher between the ages $40-79$ years, but the $95 \%$ confidence intervals were overlapping, though only marginally in the age group 70-79 years.

All except eleven patients, including 8 lobar and 1 cerebellar haematomas who had neurosurgical evacuation of the clot, had medical treatment. At the end of a median 32 month follow up, range 8 to 60 months, $103(65 \%)$ of the 158 patients had died, and of these 66 $(64 \%)$ had necropsy. The death rate immediately after onset of $\mathrm{ICH}$ was extremely high with $27 \%$ of the patients dying within 24 hours, and $50 \%$ were dead at 30 days (fig 3). Life table analysis showed that the long-term prognosis up to five years for those surviving the first month was fair (fig 4) and did not

Table 3 Location of the haematomas

\begin{tabular}{|c|c|c|}
\hline Location & \multicolumn{2}{|c|}{ No of patients (\%) } \\
\hline Lobar & & $53(34)$ \\
\hline frontal & 13 & \\
\hline temporal & 19 & \\
\hline parietal & 14 & \\
\hline occipital & 7 & \\
\hline Basal ganglionic & & $68(43)$ \\
\hline caudate nucleus & 3 & \\
\hline putamen/pallidum & 11 & \\
\hline thalamus & 28 & \\
\hline internal/external capsule & 9 & \\
\hline "basal ganglia"” & 17 & \\
\hline Cerebellum and brain stem & & $28(18)$ \\
\hline cerebellum & 17 & \\
\hline $\begin{array}{l}\text { brain stem } \\
\text { Intraventricular }\end{array}$ & & $9(5)$ \\
\hline Total & & $158(100)$ \\
\hline
\end{tabular}

differ from that of the average 1985 Finnish population. ${ }^{18}$ Six $(4 \%)$ of the patients alive 10 days or longer after the first haemorrhage had a recurrent ICH diagnosed by CT or necropsy, and another five had recurrent ischaemic or non-defined acute stroke. The recurrent ICHs occurred from 36 to 1210 days (median 304 days) after the first bleed.

Eighty three $(81 \%)$ of all 103 deaths were due to the first ICH and $84 \%$ of these occurred during the first week after onset, and an additional $4(4 \%)$ patients died of a recurrence. Heart disease, pneumonia and recurrent ischaemic or non-defined stroke were the cause of death in $12(12 \%)$ cases, and four patients died from miscellaneous causes. Age had no impact on the case fatality rate during the first month after onset but younger patients had a better long-term prognosis; $45 \%$ of patients younger than 70 years, $27 \%$ of those aged $70-79$ years, and $23 \%$ of the patients older than 80 years were alive at the end of follow up.

The cumulative frequencies of the volumes of supratentorial haematomas are shown in fig 5 . The curves of patients dead or alive at the end of follow up overlap up to $20 \mathrm{ml}$ which is explained by the small haematomas of patients dying from causes other than PICH; 15 out of 18 had haematomas $<20 \mathrm{ml}$. The volume distribution of patients dying of PICH was markedly different from that of survivors, and the difference was further exaggerated when the deaths during 30 days, and especially 7 days after onset were analysed separately. The median volumes of the patient groups were as follows: survivors $23 \mathrm{ml}$ (95\% CI 13-37 ml), ICH deaths $63 \mathrm{ml}$ (95\% CI 50-76 ml), deaths within 30 days $69 \mathrm{ml}(95 \%$ CI $50-80 \mathrm{ml})$, and within 7 days $74 \mathrm{ml}$ (95\% CI 56-86 ml).

The 30 day case fatality rate was strongly associated with the supratentorial haematoma volume $\left(\mathrm{X}^{2}=26.2 \mathrm{df}=5 \mathrm{p}<0.0005\right)$, and no critical haematoma volume was observed (fig 6). Sixteen per cent (95\% CI 6-26\%) of patients with haematomas smaller than $20 \mathrm{ml}$ died, the corresponding figure was $82 \%$ (95\% CI $60-100 \%$ ) for patients with haematomas larger than $100 \mathrm{ml}$. The number of infratentorial haematomas with CT examination was only 16 and this precludes detailed analysis. However, there was a clear difference between those dying within 30 days, and those surviving for longer-the median volumes being $18.5 \mathrm{ml}(95 \% \mathrm{CI} 15-28 \mathrm{ml})$ and $2 \mathrm{ml}$ ( $95 \%$ CI $1-8 \mathrm{ml}$ ), respectively.

The displacement of midline structures in supratentorial haematomas measured from the CTs was $8.8 \mathrm{~mm}$ (SE 0.8 ) in patients dying within 30 days, and $2.4 \mathrm{~mm}$ (SE 0.3 ) in those surviving for longer than 30 days, a highly significant difference $(t=8.3 \quad d f=102$ $\mathrm{p}<0.0001)$. The displacement was, however, strongly correlated with haematoma size $(r=0.73 \mathrm{p}<0.0001)$, thus reflecting the adverse prognostic effect of large haematomas. Ventricular extension and hydrocephalus were coded as present or absent without any quantification. In the 104 supratentorial haematomas the 30 day case fatality rate was $11 \%$ if neither 
Table 4 Age and sex specific. annual incidence rates (95\% confidence interval) per 100000 population of primary intracerebral haemorrhage in fyväskylä and surrounding communities, Central Finland, 1985-89

\begin{tabular}{|c|c|c|c|c|c|c|}
\hline \multirow[b]{2}{*}{ Age } & \multicolumn{2}{|c|}{ Men } & \multicolumn{2}{|c|}{ Women } & \multicolumn{2}{|l|}{ Total } \\
\hline & $N$ & Rate & $N$ & Rate & $N$ & Rate \\
\hline $\begin{array}{l}-39 \\
40-49 \\
50-59 \\
60-69 \\
70-79 \\
80+ \\
\text { Total }\end{array}$ & $\begin{array}{r}1 \\
11 \\
12 \\
19 \\
32 \\
3 \\
78\end{array}$ & $\begin{array}{c}2(0-12) \\
31(16-56) \\
51(26-88) \\
108(65-168) \\
320(219-451) \\
107(22-317) \\
32(25-40)\end{array}$ & $\begin{array}{r}1 \\
3 \\
8 \\
21 \\
28 \\
19 \\
80\end{array}$ & $\begin{array}{c}2(0-13) \\
9(2-25) \\
31(13-60) \\
82(51-125) \\
153(102-221) \\
266(158-421) \\
31(24-38)\end{array}$ & $\begin{array}{r}2 \\
14 \\
20 \\
40 \\
60 \\
22 \\
158\end{array}$ & $\begin{aligned} 2 & (0-8) \\
20 & (11-33) \\
40 & (24-62) \\
92 & (66-125) \\
212 & (162-273) \\
222 & (137-339) \\
31 & (27-37)\end{aligned}$ \\
\hline
\end{tabular}

was present, $36 \%$ in cases of ventricular extension, and $78 \%$ when both ventricular extension and hydrocephalus were present. This trend was highly significant (chi-square $=33.0 \mathrm{df}=2 \mathrm{p}<0.0005)$. The median volumes of the haematomas of patients dying within 30 days with either ventricular extension alone or combined with hydrocephalus was twice the size of patients without these signs on CT (table 5). Conversely, those surviving for more than 30 days had small haematoma volumes (10 to $19 \mathrm{ml}$ ) in all three patient categories, which again stresses the importance of the haematoma volume as a decisive factor of the prognosis.

The case fatality rate, all patients included, varied according to the location of the haematoma and the proportions of deaths during the first 30 days was as follows: lobar $43 \%$ (23/53), deep basal ganglionic $47 \%$ (32/68), cerebellum and brain stem $64 \%(18 / 28)$, and primary intraventricular $78 \%(7 / 9)$. The difference between supratentorial, infratentorial and primary intraventricular haemorrhage was statistically significant (chi-square $=6.0 \mathrm{df}=2$ $\mathrm{p}<0.05$ ).

At the end of the follow up 55 patients were still alive. Twenty eight $(51 \%)$ of them were

Figure 3 Probability of surviving the first 30 days after onset of primary intracerebral haemorrhage.

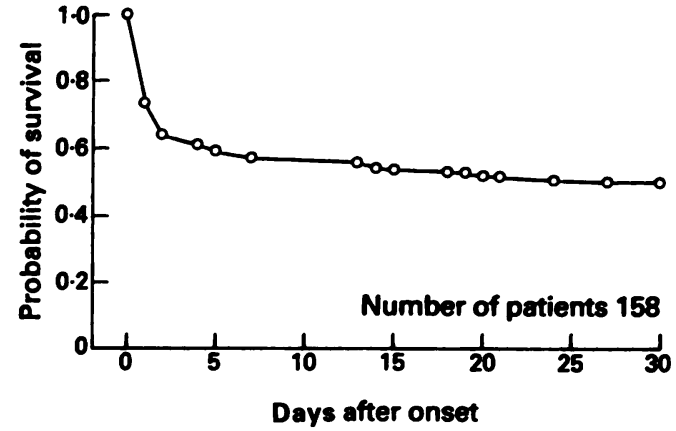

Figure 4 Probability of surviving five years afier onset of primary

intracerebral haemorrhage. Life table analysis, number of patients in brackets. The upper curve represents an average Finnish population of same age and sex distribution. independent in the ADL (Rankin grades 1 and 2), $25(45 \%)$ were in need of outside help (Rankin grades 3 and 4 ), and $2(4 \%)$ were in institutions for the chronically ill needing constant nursing care (Rankin grade 5). The functional outcome of all patients surviving for 10 days or longer was age-dependent (fig 7), the proportion of patients needing outside help in the ADL (Rankin grades 3-5) was much higher in the oldest age group than in the younger $($ chi-square $=18.8 \mathrm{p}<0.0005)$.

At the end of the follow up most of the severely handicapped patients had died but the adverse effect of old age was obvious (chisquare $=10.0 \mathrm{p}<0.005)$. Neither the location nor the volume of the haematoma had any predictive value on the functional recovery. Figure 8 depicts a summary of the fate of all 158 patients included in the study during the follow up of median 32 months.

\section{Discussion}

There are not many population based studies on PICH with CT or necropsy confirmation in a large proportion of the cases. The most important non-oriental studies ${ }^{1-9}$ with more than twenty patients are given in table 6 . The crude annual incidence rates have varied between 11-20/100 000 population, with one exception from Söderhamn, Sweden, ${ }^{4}$ giving a rate of $38 / 100000$ population. The low incidence rates in two studies ${ }^{78}$ may be explained by incomplete case ascertainment, for example, patients treated by neurosurgeons were not included, and the high rate from Söderhamn may be due to the older age structhie of the study population. To make the incidence rates comparable, five of the earlier studies where the data were available 2469 were adjusted by age to the 1980 population of Finland. In two of the studies the rates changed markedly reflecting the young ${ }^{2}$ and older $^{4}$ age structure of the study population. After the adjustment the incidence rate $32 / 100000$ of our study was the highest, but the $95 \%$ confidence interval $(27-37 / 100000)$ overlapped with those of the Libyan ${ }^{2}$ and Söderhamn ${ }^{4}$ studies, 18-31/100000 and

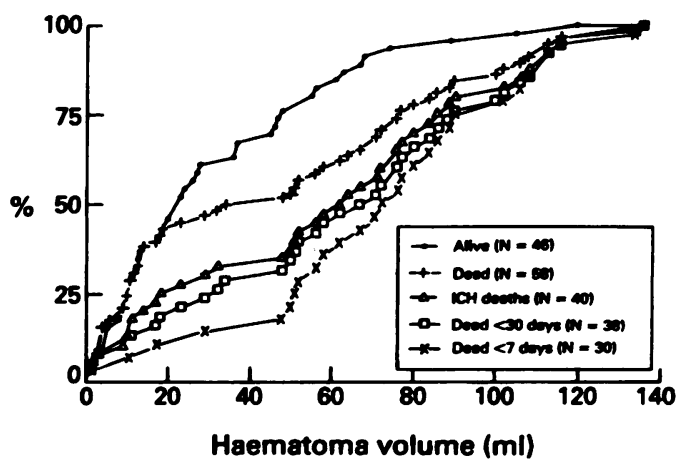

Figure 5 Cumulative distribution of supratentorial haematoma volumes of patients alive at the end of follow up, dead of any cause, and dead due to primary intracerebral haemorrhage. Of the latter, the deaths within 30 and seven days are separated. 


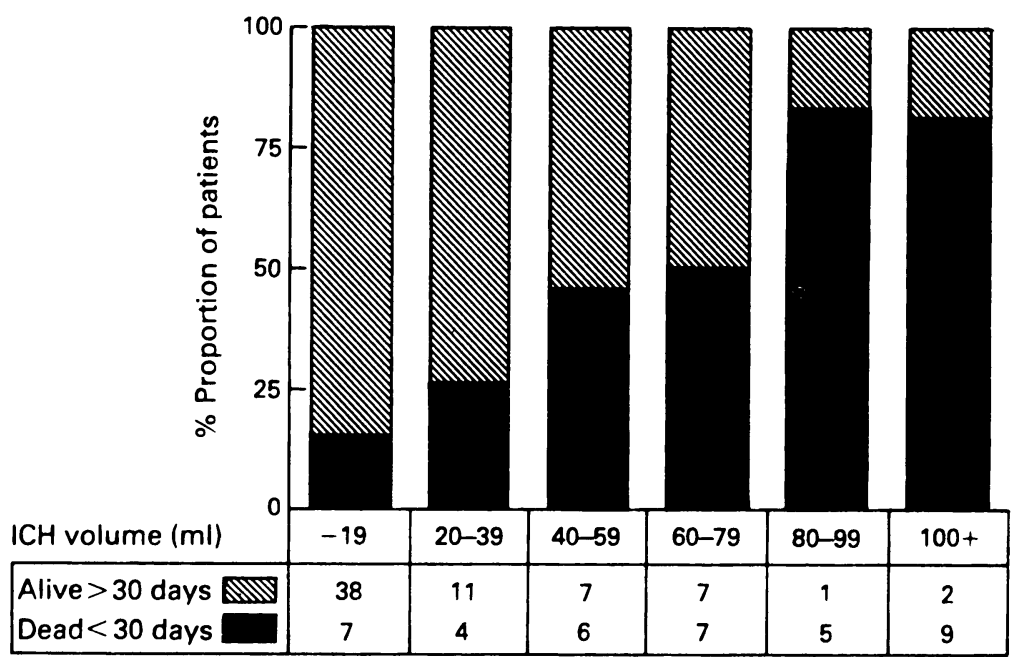

Figure 6 Proportion of patients dead within the first 30 days of onset, by supratentorial haematoma volume.

Table 5 Median volumes (ml) of supratentorial haematomas, by intraventricular cxtension, presence of hydrocephalus, and survizal

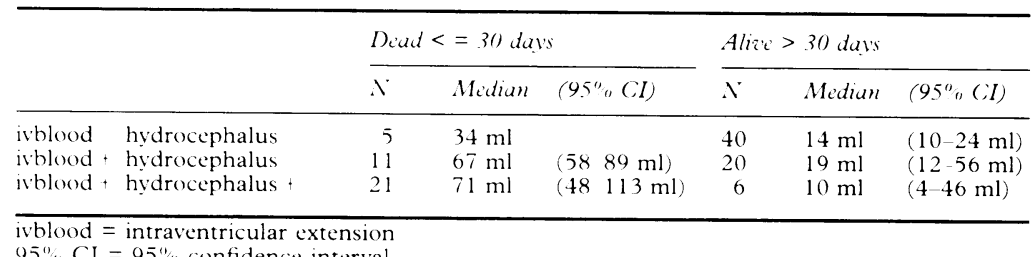

(95)

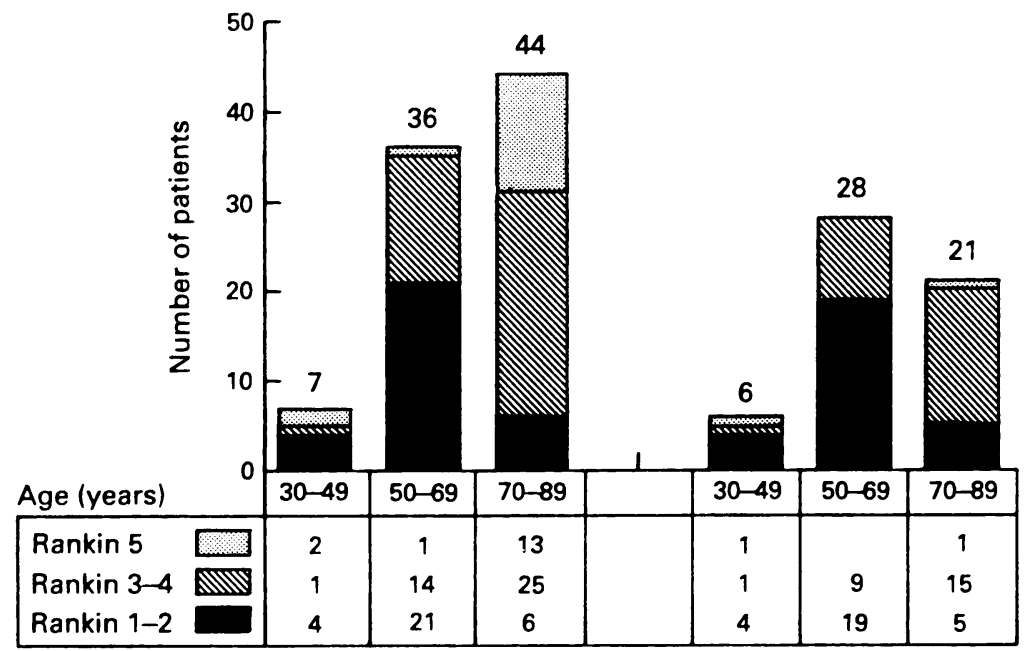

Alive $>9$ days

Survivors

Figure 7 Distribution of the functional status of patients alive 10 days or longer after onset of symptoms, and of those alive at the end of median 32 month follow up, by age. Rankin 1-2 = independent, Rankin 3-4 = needs some outside help in the ADL, Rankin $5=$ needs continuous nursing care.

$18-36 / 100000$ respectively. Thus the high incidence rate obtained from the Jyväskylä Region does not mean a real difference compared with the other studies and may be explained by a more detailed case finding which resulted from the tradition in Finland to treat all strokes in hospital; the high (92\%) admission rate from the Jyväskylä Region to the Department of Neurology (almost all stroke patients admitted had a CT); and the access to all medical and medico-legal necropsy records of the study population.

The medico-legal necropsies revealed that $5 \%$ of the patients died a sudden death which constitutes an important aspect of PICH as it occurs in the population. The high incidence rate in this study may be an underestimate because there may have been some PICH patients who did not have CT or necropsy. However, some patients with secondary, intrainfarct haematomas ${ }^{19}$ may be included in the study. We did not see such cases, perhaps because the CT examinations were seldom performed during the first few hours after onset of symptoms, and the examination was only occasionally repeated in spite of worsening of symptoms in case the initial CT was normal or suggested brain infarction. We believe that such secondary haematomas in ischaemic brain infarctions must be rare, which seems to be the case in the Stroke Data Bank with less than $1 \%$ of PICHs having a normal first CT and an $\mathrm{ICH}$ in repeat examination. $^{20}$

The early case fatality rate (CFR) was high with $27 \%$ dying during the first day, and $50 \%$ (95\% CI 42-58\%) dying within 30 days (fig 3), almost exclusively due to the first PICH. In earlier population based studies ${ }^{257921}$ the 30 day (one study 21 days) CFRs have varied between $25 \%$ and $72 \%$, with a weighted mean of $48 \%$ (95\% CI $42-54 \%$ ), which corresponds well with our results. In studies based on hospital materials ${ }^{2022}{ }^{28}$ CFRs have been from $27 \%-54 \%$ with a weighted mean of $35 \%(95 \%$ CI $32-38 \%$ ). In three of the studies the data were given for days 14,16 and 60 . The figures from hospital based studies are much lower than ours and may be explained by the numerous cases diagnosed by necropsy included in our study.

The most important determinant of death during the first 30 days in our study was haematoma volume, concerning both supraand infratentorial haematomas. The same has been shown in earlier studies ${ }^{822426}{ }^{34}$ regardless of method used in assessment of the volume. The method we used gives a fairly reliable quantitative measure of the volume, and we found that the risk of early death increased almost linearly with the haematoma volume. Because the measurement was based on one single examination, the possibility of a later increase of the volume, ${ }^{35}{ }^{36}$ may distort the results. The resolving of the haematomas ${ }^{37}$ was not a problem due to the early timing of the CT examination.

The lateral shift of the midline structures in supratentorial haematomas correlated closely with the haematoma volume and does not have any predictive value in itself. Ventricular extension of the haematoma tripled the early CFR, and when hydrocephalus was also present the rate was sevenfold. The haematoma volumes in these cases were, however, three times larger than in patients without these signs. The median haematoma volumes of survivors, with or without ventricular extension or hydrocephalus, were small and of similar size, between $10 \mathrm{ml}$ and $20 \mathrm{ml}$. Ventricular extension has 


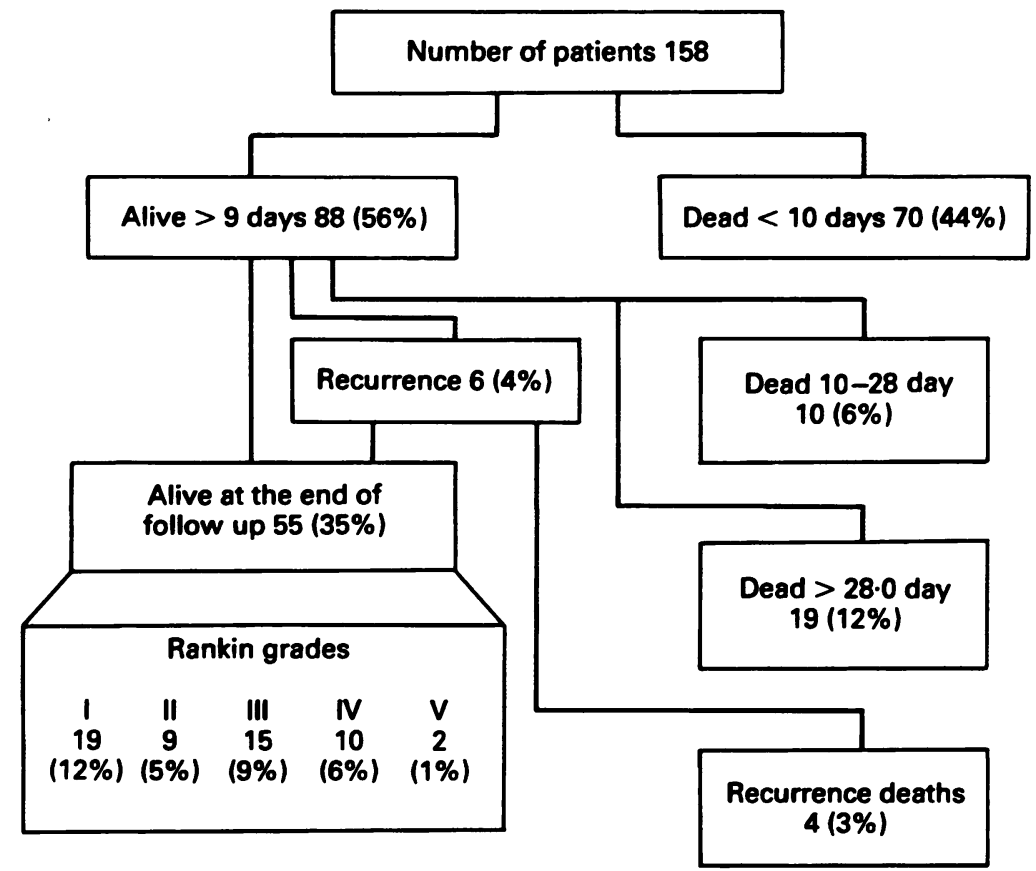

Figure 8 The fate during the median follow up of 32 months of all 158 patients included in the study. The percentages refer to the initial 158 patients.

generally been considered as an adverse prognostic sign, and several studies have demonstrated higher CFRs when ventricular blood has been present; $22427-30333438$ in some of the studies ${ }^{27} 30$ this has been associated with large haematoma size. No generally accepted explanation of the adverse effects of ventricular extension has been proposed but we think it only reflects the large haematoma volume. The adverse effects of hydrocephalus on outcome has been observed in a few studies ${ }^{33}{ }^{34}$ but no explanation for this has been proposed. Profuse intraventricular bleed blocking the CSF circulation and causing hydrocephalus increasing the intracranial pressure which further worsens the condition seems to us plausible, although it has not been accepted as the sole explanation. ${ }^{34}$ In our study, age had no role in predicting the CFR during the first month.

Haematoma location had some effects on the acute survival, patients with large basal ganglia haematomas, infratentorial haematomas, and primary intraventricular haemorrhages had higher CFRs than patients with haematomas of other locations.
If the patient survived the first month the probability of surviving five years was similar to an average Finnish population of the same age and sex distribution. After a mean follow up of 32 months, $35 \%$ of the patients were alive. In none of the earlier epidemiological studies has the follow up been longer than 12 months. Three of the hospital series ${ }^{232730}$ give data on 2.5 to five year survival, $21 \%$ to $60 \%$ of patients being alive. The most frequent causes of death after the first month were cardiac disease, pneumonia and recurrent strokes. Old age $>70$ years was associated with a poor long term survival.

The functional outcome was assessed in patients alive 10 days or longer after onset. Old age was strongly associated with severe handicap during the first weeks and months after stroke (fig 5). During follow up the most seriously disabled patients died, and $51 \%$ of the 55 patients alive at the end of follow up were independent, $45 \%$ needed outside help in the ADL, and only $4 \%$ were in need of constant nursing care. In the Oxfordshire study ${ }^{6}$ applying the Rankin grading system, $68 \%$ of the one year survivors were functionally independent, the corresponding figure in one hospital based study ${ }^{26}$ with CT confirmation of the diagnosis was $75 \%$. The difference in our results may be explained by selection factors, the most ill patients perhaps not being admitted to the highly specialised hospitals.

Our results show that PICH is more common than earlier studies have suggested. Every fourth patient is either found dead or dies within the first day, often during the first hours after onset of symptoms. Only primary preventive measures, for example, antihypertensive treatment, and the avoidance of excessive amounts of alcohol ${ }^{3940}$ would decrease the number of patients in this category. If the patient lives long enough to have the diagnosis confirmed medical treatment aimed at decreasing the intracranial pressure and preventing complications must be given, and surgical treatment contemplated in spite of lacking consensus about the indications. ${ }^{4142}$ The results of our study stress the importance of primary preventive measures but after the catastrophe has occurred, we need better therapeutic tools than those available today to improve the probability of survival, and the functional outcome of the survivors.

Table 6 Previous non-oriental studies on the incidence of spontaneous intracerebral haemorrhage. Place and years of study, study population, number of patients, annual crude and adjusted incidence rates (per 100000 population), and percentages with CT confirmation

\begin{tabular}{|c|c|c|c|c|c|c|c|}
\hline \multirow[b]{2}{*}{ Place } & \multirow[b]{2}{*}{ Year } & \multirow[b]{2}{*}{ Population } & \multirow[b]{2}{*}{ No } & \multicolumn{2}{|l|}{ Rate } & \multirow[b]{2}{*}{$C T(\%)$} & \multirow[b]{2}{*}{ Comments } \\
\hline & & & & Crude & $\operatorname{adj}^{*}$ & & \\
\hline $\begin{array}{l}\text { Lehigh Valley/USA }{ }^{1} \\
\text { Benghazi/Libya } \\
\text { Cincinnati/USA }^{3} \\
\text { Söderhamn/Sweden } \\
\text { Rochester/USA } \\
\text { Oxfordshire/UK } \\
\text { Oxford }^{6} \\
\text { Lund/Sweden } \\
\text { Giessen/Germany }^{8} \\
\text { Tilburg/Netherlands } \\
\text { Present study }\end{array}$ & $\begin{array}{l}1982-83 \\
1983-84 \\
1982 \\
1983-86 \\
1975-84 \\
1981-86 \\
1986-87 \\
1987 \\
1978-80 \\
1985-89\end{array}$ & $\begin{array}{r}580000 \\
519000 \\
1400000 \\
31000 \\
60000 \\
105000 \\
153000 \\
235000 \\
151000 \\
116000\end{array}$ & $\begin{array}{r}83 \\
63 \\
131 \\
35 \\
80 \\
66 \\
28 \\
27 \\
54 \\
158\end{array}$ & $\begin{array}{l}18 \\
12 \\
14 \\
38 \\
14 \\
16 \\
11 \\
12 \\
18 \\
31\end{array}$ & $\begin{array}{l}\frac{16}{24} \\
\frac{26}{16} \\
\frac{16}{19} \\
32\end{array}$ & $\begin{array}{r}? \\
80 \\
100 \\
37 \\
70 \\
59 \\
86 \\
100 \\
56 \\
78\end{array}$ & $\begin{array}{l}\text { "haemorrhagic strokes" } \\
\text { "haemorrhagic strokes" } \\
\text { whites only included } \\
\text { aged population } \\
\text { CT performed in } 25-85 \% \\
\text { necropsy in } 29 \% \\
\text { cases missing } \\
\text { cases missing } \\
\text { CT + isotope scan } \\
\text { necropsy in } 22 \%\end{array}$ \\
\hline
\end{tabular}

*) Adjusted to the age distribution of the Finnish 1980 population 
1 Alter M, Sobel E, McCoy RL, et al. Stroke in the Lehigh Valley: Incidence based on a community-wide hospital register. Neuroepidemiology 1985;4:1-15.

2 Ashok PP, Radhakrishnan K, Sridharan R, El-Mangoush MA. Incidence and pattern of cerebrovascular disease in Benghazi, Libya

3 Brott T, Thalinger $K$, Hertzberg V. Hypertension as a risk factor for spontaneous intracerebral hemorrhage. Stroke 1986;17:1078-83.

4 Terent A. Increasing incidence of stroke among Swedish women. Stroke 1988;19:598-603.

5 Broderick JP, Phillips SJ, Whisnant JP, O'Fallon WM, Bergstralh EJ. Incidence rates of stroke in the eighties: The end of the decline in stroke? Stroke 1989; 20:577-82.

6 Bamford J, Sandercock P, Dennis M, Burn J, Warlow C. A prospective study of acute cerebrovascular disease in the community: the Oxfordshire Community Stroke Project1981-86. 2: Incidence, case fatality rates and overall outcome at one year of cerebral infarction, primary outcome at one year of cerebral infarction, primary
intracerebral and subarachnoid haemorrhage. $f$ Neurol Neurosurg Psychiatry 1990;53:16-22.

7 Westling B, Norrving B, Thorngren $M$. Survival following stroke. A prospective population-based study of 438 hospitalized cases with prediction according to subtype, severity and age. Acta Neurol Scand 1990;81:457-63.

8 Schutz H, Bödeker R-H, Damian M, Krack P Dorndorf W. Age-related spontaneous intracerebral hematoma in a German community. Stroke 1990;21: 1412-18.

9 Herman B, Leyten ACM, van Luijk JH, Frenken CWGM, Op de Coul AAW, Schulte BPM. Epidemiology of stroke in Tilburg, The Netherlands. The population-based stroke incidence register: 2 . Incidence, initial clinical picture and medical care, and three-week case fatality. Stroke 1982; 13:629-34.

10 Rankin J. Cerebral vascular accidents in patients over the age of 60: II. Prognosis. Scot Med f 1957;2:200-15.

11 Candelise L, Pinardi G, Aritzu E. Stroke disability assessed by telephone interview: Reliability and reproducibility. $\mathcal{J}$ Neurol 1990;237:143.

12 Kretschmann HJ, Weinrich W. Neuroanatomy and cranial computed tomography. New York: Thieme, 1986.

13 Schoenberg BS. Calculating confidence intervals for rates and ratios. Neuroepidemiology 1983;2:257-65.

14 Campbell MJ, Gardner MJ. Calculating confidence intervals for some non-parametric analyses. In: Gardner MJ, Altman DG. Statistics with confidence, confidence intervals and statistical guidelines. London: BMF 1989;71-9.

15 Gardner MJ, Altman DG. Calculating confidence intervals for proportions and their differences. In: Gardner MJ Altman DG. Statistics with confidence, confidence intervals and statistical guidelines. London: BMF 1989;28-33.

16 Colton T. Statistics in medicine. Boston: Little, Brown, 1974:237-50.

17 Central Statistical Office of Finland. Statistical Yearbook of Finland 1981. Helsinki: 1981.

18 Central Statistical Office of Finland. Life tables 1985. Helsinki: 1987.

19 Bogousslavsky J, Regli F. Early spontaneous intra-infarct hematoma (ESIH): Is primary cerebral hemorrhage overdiagnosed? Neurology 1991 (suppl 1):387.

20 Foulkes MA, Wolf PA, Price TR, Mohr JP, Hier DB. The Stroke data Bank: Design, methods, and baseline characteristics. Stroke 1988;19:547-54.

21 Bamford J, Dennis M, Sandercock P, Burn J, Warlow C. The frequency, causes and timing of death within 30 days of a first stroke: the Oxfordshire Community Stroke Project. Neurol Neurosurg Psychiatry 1990;53:824-9.

22 Portenoy RK, Lipton RB, Berger AR, Lesser ML, Lantos
G. Intracerebral haemorrhage: a model for the prediction of outcome. I Neurol Neurosurg Psychiatry 1987;50:

23 Chambers BR, Norris JW, Shurvell BL, Hachinski VC. Prognosis of acute stroke. Neurology 1987;37:221-5.

24 Senant J, Samson M, Proust B, Szeibert J, Onnient Y Approche multi-factorielle du pronostic vital des hématomes intra-cérérbraux spontanés. Rev Neurol (Paris) 1988;144:279-83.

25 Schutz HJ, Oehler KU. Die Bedeutung kardiovaskuläre Risikofaktoren für die Prognose spontaner intrazerebrale Hämatome. Nervenarzt 1985;56:328-30.

26 Fieschi C, Carolei A, Fiorelli M, et al. Changing prognosis of primary intracerebral hemorrhage: Results of a clinical and computed tomographic follow up study of 104 patients. Stroke 1988;19:192-5.

27 Helweg-Larsen S, Sommer W, Strange P, Lester J, Boysen G. Prognosis for patients treated conservatively for spontaneous intracerebral hematomas. Stroke 1984 15:1045-8.

28 Daverat P, Castel JP, Dartigues JF, Orgogozo JM. Death and functional outcome after spontaneous intracerebral hemorrhage. A prospective study of 166 cases using multivariate analysis. Stroke $1991 ; 22: 1-6$

29 Tuhrim S, Dambrosia JM, Price TR, Mohr JP, Wolf PA Heyman A, Kase CS. Prediction of intracerebral hemorrhage survival. Ann Neurol 1988;24:258-63.

30 Douglas MA, Haerer AF. Long-term prognosis of hypertensive intracerebral hemorrhage Stroke 1982;13: 488-91.

31 Dollberg S, Rosin AJ, Fisher D. A new look at the natural history and clinical features of intracerebral haemorrhage: A clinical CT scan correlation. Gerontology 1986; 32:211-6.

32 Kase CS, Williams JP, Wyatt DA, Mohr JP. Lobar intracerebral hematomas: Clinical and CT analysis of 22 cases. Neurology 1982;32:1146-50.

33 Rádberg JA, Olsson JE, Rådberg CT. Prognostic parameter in spontaneous intracerebral hematomas with special reference to anticoagulant treatment. Stroke 1991, 22:571-6.

34 Young WB, Lee KP, Pessin MS, Kwan ES, Rand WM Caplan LR. Prognostic significance of ventricular blood in supratentorial hemorrhage: A volumetric study. Neurology 1990;40:616-9.

35 Broderick JP, Brott TG, Tomsick T, Barsan W, Spilker J. Ultra-early evaluation of intracerebral hemorrhage. $\mathcal{F}$ Neurosurg 1990;72:195-9.

36 Chen ST, Chen SD, Hsu CY, Hogan EL. Progression of hypertensive intracerebral hemorrhage. Neurology 1989; 39:1509-14.

37 Dennis MS, Bamford JM, Molyneux AJ, Warlow CP. Rapid resolution of signs of primary intracerebral haemorrhage in computed tomograms of the brain. $B M F$ 1987;

38 Steiner I, Gomori JM, Melamed E. The prognostic value of the CT scan in conservatively treated patients with intracerebral hematoma. Stroke 1984;15:279-82.

39 Donahue RP, Abbott RD, Reed DM, Yano K. Alcohol and hemorrhagic stroke. The Honolulu Heart Program. IAMA 1986;255:2311-4.

40 Monforte R, Estruch R, Graus F, Nicolas JM, UrbanoMarquez A. High ethanol consumption as risk factor for intracerebral hemorrhage in young and middle-aged people. Stroke 1990;21:1529-32.

41 Ropper AH. Emergency management of intracerebral hemorrhage (ICH). Emergency Neurology, AAN Annual hemorrhage (ICH). Emergency Ne

42 Mendelow AD. Spontaneous intracerebral haemorrhage. $f$ Neurol Neurosurg Psychiatry 1991;54:193-5. 